This is the author's manuscript for publication. The publisher-formatted version may be available through the publisher's web site or your institution's library.

\title{
Analysis of particulate size distribution and concentrations from simulated jet engine bleed air incidents
}

Garrett W. Mann, Steven J. Eckels, and Byron W. Jones

\section{How to cite this manuscript}

If you make reference to this version of the manuscript, use the following information:

Mann, G. W., Eckels, S. J., \& Jones, B. W. (2014). Analysis of particulate size distribution and concentrations from simulated jet engine bleed air incidents. Retrieved from http://krex.ksu.edu

\section{Published Version Information}

Citation: Mann, G. W., Eckels, S. J., \& Jones, B. W. (2014). Analysis of particulate size distribution and concentrations from simulated jet engine bleed air incidents. HVAC\&R Research, 20(7), 780-789.

Copyright: (C) 2014 ASHRAE

Digital Object Identifier (DOI): doi:10.1080/10789669.2014.950922

Publisher's Link:

http://www.tandfonline.com/doi/abs/10.1080/10789669.2014.950922\#.VTFX2SHBwXA

This item was retrieved from the K-State Research Exchange (K-REx), the institutional repository of Kansas State University. K-REx is available at http://krex.ksu.edu 


\title{
Analysis of particulate size distribution and concentrations from simulated jet engine bleed air incidents
}

\begin{abstract}
Engine oil migrating into the bleed air stream of aircraft environmental control systems occurs with enough frequency and deleterious effects to generate significant public interest. While previous work has explored the chemical makeup of the contaminants in the aircraft cabin during these events, little is known about the characteristics of the aerosol resulting from oil contamination of bleed air. This paper presents particle counter data (giving both size distributions and concentration information) of the oil droplets from simulated jet engine bleed air. Four particle counters-a scanning mobility analyzer, an aerodynamic particle-sizer, an optical particle counter, and a waterbased condensation particle counter-were used in the study encompassing a size range from $13 \mathrm{~nm}$ to $20 \mu \mathrm{m}$. The aerosol characterization is given for different bleed air temperatures and pressures. The data show a substantial increase of ultra-fine particles as the temperature is increased to the maximum temperatures expected during normal aircraft operation. This increase in ultra-fine particles is consistent with smoke generated from the oil. The pressure of the bleed air had little discernible effect on the particle-size and concentration.
\end{abstract}

\section{Introduction}

Maintaining the quality of aircraft cabin air for passenger and crew health and comfort poses a significant technical challenge. The high concentration of passengers on typical commercial flights requires a substantial amount of fresh air be brought into the cabin from outside the aircraft. However, at 12,000 m (39,000 ft), outside air is typically at a temperature of $-57^{\circ} \mathrm{C}\left(-70^{\circ} \mathrm{F}\right)$ and a pressure of $20 \mathrm{kPa}(2.9 \mathrm{psia})$, conditions which are unsuitable for the cabin occupants (Hunt et al. 1995). Since the 1950s, with the introduction of the jet engine, the most common method of pressurizing and conditioning aircraft cabins has been through the use of bleed air from the aircraft jet engine compressor. Prior to fuel injection, air from the engine's compressor is bled off, cooled, and fed into the cabin to pressurize the cabin and provide ventilation air. While in general this design is a simple and effective method for cabin pressurization and ventilation, one significant drawback is that the bleed air can be contaminated by oil which is then introduced into the cabin as a potentially hazardous oil mist. The contamination can come from ingestion of the oil into the engine air inlet and, more commonly, from oil seal leaks in the compressor. Such contamination has occurred with enough frequency to generate significant public interest with frequency estimates ranging from 1 in 22,000 flights 
(Winder and Balouet 2000) to 1 in 1000 flights (Hood 2001). Certain aircraft models may have even higher rates. For example, issues with the BAe 146 prompted a senate investigation in Australia during which it was estimated that as many as 1 out of 66 BAe 146 flights experienced a bleed air incident (Australia 2000). Health effects for passengers and crew during these incidents are diverse, ranging from eye and throat irritation and blurred vision to disorientation, nausea, vomiting or even loss of consciousness (Winder and Balouet 2001). Both frequency of these events and severity of the health effects have spurred a significant amount of research. Concern about bleed air contamination led to the requirement for sensing for oil contamination in ASHRAE Standard 161 Air Quality within Commercial Aircraft. (ASHRAE 2007).

Considerable work has been done to analyze and characterize the contaminants that would likely be present in the bleed air during an incident. Multiple papers have been published identifying specific chemicals present in the oil and discussing health risks and effects of these chemicals (Winder and Balouet 2002; Van Netten 2005; Bartl et al. 2008). Additionally, contaminants, particularly volatile organic compounds (VOC) and semi-volatile organic compounds (SVOC), generated by the pyrolysis of the lubricating oil at the high temperatures expected in the bleed air system, have been identified and studied (Crane et al. 1983; Van Netten 1999; Van Netten and Leung 2000; Van Netten and Leung 2001).

Other research has focused on the problem of effectively and inexpensively detecting an incident. Possible methods of detecting an incident include monitoring carbon monoxide, carbon dioxide, or some combination of the two; monitoring miscellaneous unburned hydrocarbons; or monitoring fine or ultrafine oil particles (Overfelt et al. 2012). Fast chemical detection of carbon monoxide was studied by Buck et al (2013) with research focused primarily on whether accurate detection could be performed under non-steady conditions. Additionally, some work has been done on developing a fast electrochemical sensor for detecting tri-cresyl phosphate (TCP), which many regard as the substance responsible for the more severe health effects related to the incidents, as a potential monitoring device (Pedrosa et al. 2009).

One aspect largely missing from the bulk of research for bleed air contamination is a characterization of the oil aerosol size distribution entering the aircraft cabin during a bleed air incident. Information about the size distribution is important for several different reasons. Both the transport of oil throughout the aircraft cabin and how it is introduced into the body during an incident are determined by the particulate characteristics of the oil mist. Additionally, in the search for a safe and inexpensive real-time bleed air monitoring system, understanding particle-size distribution in the 
bleed air stream could give rise to an effective method of detecting an incident using particle counting technology instead of chemical sensors.

Obtaining particulate characteristics of a bleed air incident poses a significant technical challenge. On one hand, measuring the particulates directly from the bleed air duct of an actual operating aircraft would be ideal, providing data that directly characterize the real system. However, complications and cost of this approach are prohibitive. It would be impractical to outfit enough regular flights with delicate, expensive instruments to have a high statistical chance of recording an oil event. Chartering an entire aircraft and outfitting it to have artificial oil incidents would also be costly and could create serious safety risks related to purposely forcing oil into the engine. One previous study was found in the literature where oil was injected into a laboratory-mounted auxiliary power unit (APU) (Crane et al. 1983). However, only gaseous contaminants were analyzed; no aerosol characterization measurements were collected.

In this study, particulate size characteristics of a bleed air incident are analyzed through the use of a bleed air simulator (BAS). There are multiple routes by which oil could be introduced into a jet engine compressor including direct ingestion and leaking from shaft seals. Furthermore, any of these mechanisms could have widely different size generation characteristics depending on the nature of the ingestion or leak. What is certain, however, is that the high shear forces within the compressor will finely aerosolize any liquid that enters the compressor. Repeated sharp bends in the stream lines as the air is accelerated and decelerated by each rotor-stator stage would cause many, if not most, droplets to impact the rotor blades and stator vanes only to be re-aerosolized by surface shear forces. Due to these factors, it is very likely that the oil aerosol distribution leaving the compressors is in a finely aerosolized state. However, a point of significant interest is what happens to this fine oil aerosol as it is exposed to the high temperature and pressure from the compressed air. Thus, in this study, a bleed air simulator is used to generate a polydisperse sub-micron aerosol and subject it to the temperatures and pressures similar to those found in commercial aircraft compressors during typical operation. While significant work has been done studying the characteristics of aerosols generated from combustion — see (Lighty, Veranth et al. 2000) for a review—works studying the effect of temperature and pressure on pre-combustion oil aerosols could not be found in the literature. The closest similar work studied the relationship between cooking oil temperature and generated aerosol size and concentration (Siegmann and Sattler 1996). This work differs from the current study in terms of the conditions studied (a narrower range of temperatures and no applied pressure) as well as in the fact that the aerosol is generated 
by elevated temperature instead of being generated mechanically and then exposed to elevated temperature as in the current study.

The study reported in this paper addressed the effect of temperature and pressure on the particle-size distributions and concentrations of particulates measured from a bleed air stream in a BAS. After a brief discussion of the BAS and particle-measuring instruments used in the study, this paper presents and discusses particulate characteristics for various temperatures and pressures representing bleed air conditions for the normal operation of an aircraft.

\section{Typical bleed air system}

In the bleed air system of a typical modern aircraft, air is extracted from the engine compressor at two ports, an intermediate stage and a high pressure stage. A pressure-control valve selects between these two ports to provide air at the appropriate pressure (about 200kPa, 29psi) to the air-conditioning packs (Hunt et al. 1995). The air coming from the compressor can be at a high temperature, $>300^{\circ} \mathrm{C}\left(572{ }^{\circ} \mathrm{F}\right)$, due to the heat of compression. A precooler, situated immediately after the pressure-control valve, cools the air to a temperature below the flash temperature of jet fuel for safety. The bleed air then moves to the air-conditioning packs where it is further conditioned and added to the cabin at about $15^{\circ} \mathrm{C}\left(59^{\circ} \mathrm{F}\right)$ and $81 \mathrm{kPa}(11.7 \mathrm{psi})$ (Hunt et al. 1995). The pressures and temperatures of the bleed air coming from the main engine compressor prior to the precooler can vary widely during the engine operation due to the different operating conditions for the engine.

\section{Bleed air simulator}

The BAS used in this study consists of three parts: the droplet generation portion composed of an aerosol generator, the compressor and heater tube section used to increase the temperature and pressure of the aerosol, and the main duct used to cool and dilute the flow of the bleed air to make it suitable for sampling. Further details about the design, construction, and use of this device are given by Magoha (2012) and Eckels, et al. (2014).

Figure 1 illustrates the aerosol generation portion of the system in which new jet engine oil ${ }^{1}$ is atomized into an air stream with an aerosol generator to form a poly-dispersed sub-micron aerosol. The two control valves in the aerosol generator allow the concentration of the aerosol to be controlled. Solenoid Valve 2 allows the generator to be bypassed if no oil is desired in the flow or to purge the aerosol from the system during startup and shutdown.

\footnotetext{
${ }^{1}$ Mobil Jet Oil II
} 


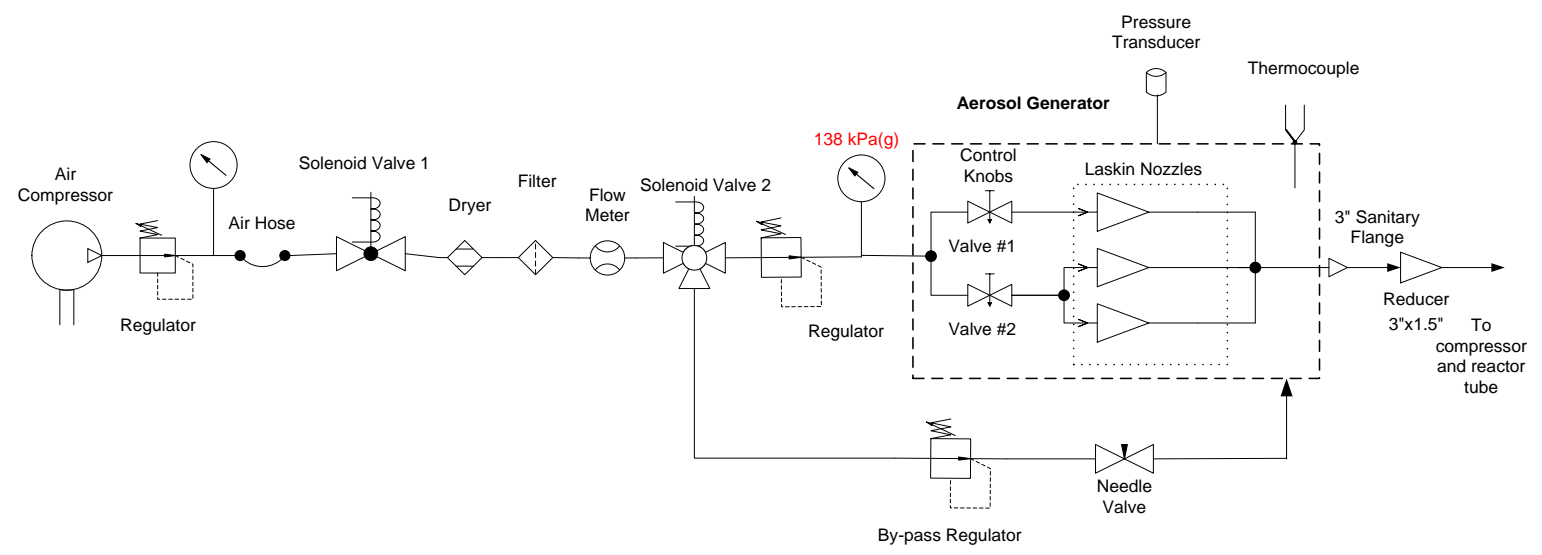

Figure 1. Aerosol generation portion of the bleed air simulator

After the aerosol is generated, it flows into the compressor and heater tube assembly (Figure 2) where temperature and pressure of the flow are increased. At the compressor inlet, two check valves are installed in opposite directions to keep the pressure of the aerosol between $20 \mathrm{kPa}(3 \mathrm{psi})$ above and $34 \mathrm{kPa}$ (5psi) below atmospheric pressure. Clean air is either added or aerosol is removed from the system through the HEPA filter to maintain this condition. The aerosol then moves through the reciprocating compressor, which increases the pressure of the stream based on the setting of the back pressure regulator. To allow the temperature of the pressurized air to be controlled to different operating conditions, after the compressor, the flow enters a heater tube - a stainless steel tube wrapped with electric heaters. The heaters provide an approximately constant heat flux to the flow which can be adjusted by changing the voltage on the heater via a variable transformer. The length of the heater tube was designed to give a residence time roughly similar to that of the bleed air between the outlet of the compressor and the entrance to the bleed air precooler in an actual aircraft.

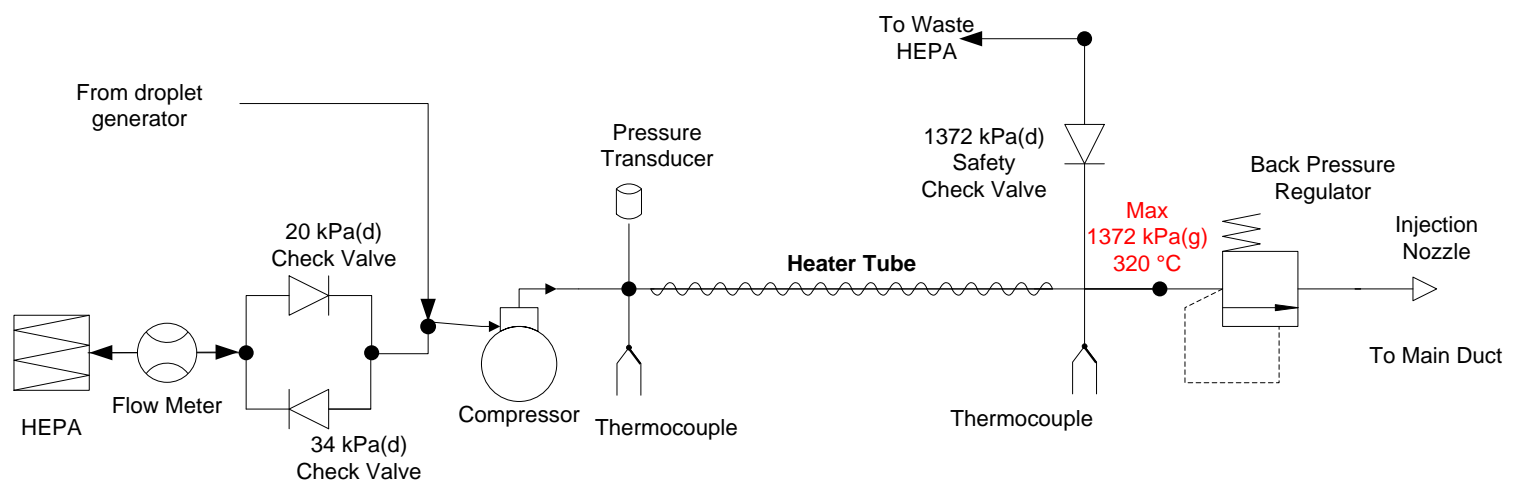

Figure 2. Compressor and heater tube portion of simulator 
After the flow is pressurized and heated, it is injected into an air stream in the main duct, a converted ASHRAE 52.2 test rig (Figure 3). This apparatus was originally designed to generate an aerosol with appropriate concentrations to simulate exposures for aircraft recirculation filters and dilution of the flow from the aerosol generator was required. This dilution is also required to provide concentrations that are low enough to not saturate some of the particle counting instruments. The dilution with room air also cools the aerosol which quenches any chemical reactions and lowers the temperature to be compatible with the measuring equipment. The HEPA filters also prevent the lab air from being contaminated. Air flows through the square cross-sectional duct $(610 \times 610 \mathrm{~mm}, 2 \times 2 \mathrm{ft})$ at approximately $0.47 \mathrm{~m}^{3} / \mathrm{s}$ (1000 cfm), forced by a high-pressure blower. Immediately after the blower, the air is pre-filtered by a HEPA filter, and the aerosol from the droplet generator is injected into the flow stream. Further down the duct, after passing through a mixing plate, the condensation particle counter (CPC), aerodynamic particle-sizer (APS), and scanning mobility particle-sizer spectrometer (SMPS) particle counters sample the flow. The air is then filtered through another HEPA filter and exhausted out of the system. Pickoffs for the particle counters were sized to be isokinetic. During the design of the system, the optical particle counter (OPC) was initially overwhelmed by the concentration of the particles in the duct, even when only one atomizing nozzle was being used. Therefore, a diluter was added to the system. This diluter consists of a PVC bypass pipe and valve assembly. Clean air from after the first HEPA filter is routed into this pipe. The bypass pickoff injects aerosol into this line, and the OPC samples the resulting mixture directly from the line. A gate valve in the bypass line controls the dilution ratio of the diluter. This ratio was found through calibration to be 70:1. The CPC, APS, and SMPS particle counters did not become overwhelmed with particles even though they sampled from the main flow.

The pressure of the simulated bleed air after the compressor is measured by a $0-3447 \mathrm{kPa}(0-500$ psia) pressure transducer with $\pm 0.11 \%$ full scale accuracy. The temperature of the bleed air after the heater tube is measured by a high temperature type $\mathrm{K}$ thermocouple with an uncertainty of $\pm 1^{\circ} \mathrm{C}$. 


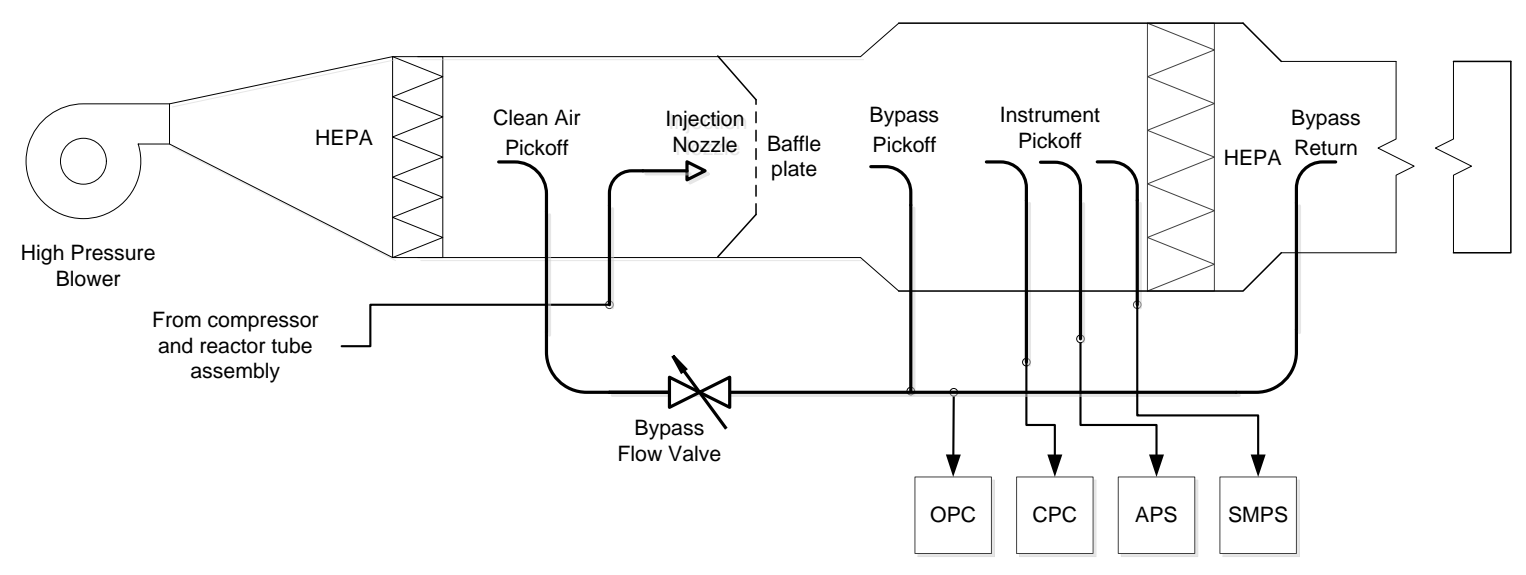

Figure 3. Main duct and sampling portion of simulator

\section{Particle counters}

The four different particle counters were used to characterize the bleed air from the engine simulator. A description of each of the particle counters is given below:

Aerodynamic Particle-sizer (APS) $)^{2}$ This instrument measures the aerodynamic diameter of individual particles by accelerating the particle stream through a nozzle and recording the time it takes each particle to accelerate through the flow. These time-of-flight data are measured for individual particles to infer the distribution of aerodynamic diameter and particle concentration. The particle-size is binned into 52 channels from $0.532 \mu \mathrm{m}$ to $20 \mu \mathrm{m}$. The manufacturer uncertainty for the APS is $\pm 0.03 \mu \mathrm{m}$ for size and $\pm 10 \%$ of the reading for concentration.

Optical Particle Counter $(\mathrm{OPC})^{3}$ : The OPC measures particle-size and concentration by recording the intensity of light scattered by the particles as they pass one by one past the detector. The geometric size of the particle is inferred from the intensity of the scattered light. The particle-size is binned into 16 channels from $0.3 \mu \mathrm{m}$ to $10 \mu \mathrm{m}$. The manufacturer uncertainty for the OPC is $\pm 3.5 \%$ for size with no listed uncertainty for concentration.

Condensation Particle Counter $(C P C)^{4}$ : This instrument measures the concentration of nanometer-sized particles by passing the particle stream through a supersaturated air/water vapor mixture. Water condenses on the particles, causing them effectively to grow in size. The resulting water droplet is then counted with an optical detector similar to the OPC. Particles as small as $6 \mathrm{~nm}$ are detected. There is no binning. This instrument was chosen because it does

\footnotetext{
${ }^{2}$ TSI Model 3321

${ }^{3}$ Climet Spectro 0.3

${ }^{4}$ TSI Model 3781
} 
not use a flammable condensate and thus could be safely used in aircraft applications. The manufacturer uncertainty for the CPC is $\pm 10 \%$ of the reading.

Scanning Mobility Particle-Sizer Spectrometer $(S M P S)^{5}$ : This instrument measures the particle-size distribution in the aerosol by giving the particles an electric charge and passing them through an electric field to physically separate them into streams of like diameter. The number of particles in each diameter is counted using a separate CPC that condenses butanol onto the particles and measures the reflected light. The size range is adjustable from 2.5 to $1000 \mathrm{~nm}$ with 53 bins, with the actual size range for a given configuration set somewhere inside of this range. During the bleed air testing, the size range was 13 to $542 \mathrm{~nm}$. Due to limited availability, the SMPS was only used for the base set of conditions. The manufacturer listed uncertainty for the SMPS is $\pm 3 \%$ for size and $\pm 10 \%$ for concentration.

The APS and the SMPS together measure a size range spanning from $13 \mathrm{~nm}$ to $20 \mu \mathrm{m}$. The OPC and the CPC represent lower cost alternatives for detecting and quantifying particulate characteristics. The APS and OPC measure the same size range but with different measurement techniques. Likewise, the SMPS and the stand-alone CPC both measure particles at a smaller size range, but only the SMPS is capable of binning the particulates by size. The standalone CPC only gives the particle concentration.

\section{Test Procedure}

Pressures and temperatures of bleed air on a typical aircraft vary widely depending on operational mode. There are two different bleed locations on a typical bleed air system: one at a high pressure and one at an intermediate pressure. The location where the air is bled off the engine is switched based on the pressure generated by the compressor at a given operating condition. Within these different variations, a study published by the National Research Council (2002) has identified six different bleed air conditions representative of an aircraft's operation. These conditions are listed in Table 1.

Table 1. Operating temperatures and pressures of the bleed air in a representative aircraft jet engine (National Research Council 2002)

\begin{tabular}{llll}
\hline Mode of Operation & Temperature, ${ }^{\circ} \mathbf{C}(\mathbf{F})$ & Absolute Pressure kPa, $($ PSI) & Extraction Stage \\
\hline Top of climb & $310(590)$ & $690(100)$ & Low pressure \\
Cruise & $250(490)$ & $340(50)$ & Low pressure \\
Initial descent from cruise & $185(365)$ & $200(29)$ & High pressure \\
End of descent (ground level) & $230(445)$ & $460(67)$ & High pressure
\end{tabular}

\footnotetext{
${ }^{5}$ TSI Model 3936
} 
These conditions served as a starting point for developing a test matrix. As data were collected, it became apparent that exploring further temperatures and pressures would give more insight into the characterization of the aerosols. Thus the matrix was extended to include four other sets of data: two sets representing a range of temperatures at both a low and a high constant pressure and two sets representing a range of pressures at a low and a high constant temperature. Because the temperature of the bleed air in an actual aircraft is due only to the work done on the air during compression, some of these test points may be outside of the physical limitations of an actual bleed air system. These four conditions, plus the base National Research Council-listed conditions, comprise the sum of the data taken in this work. The conditions are listed in Table 2. Note the data from Point 2 of Study 3 was omitted due to a recording failure.

Table 2. Temperature and pressure conditions

\begin{tabular}{ccccccccccc}
\hline Point \# & \multicolumn{2}{c}{ Base } & \multicolumn{2}{c}{ Study 1} & \multicolumn{2}{c}{ Study 2} & \multicolumn{2}{c}{ Study 3} & Study 4 \\
\hline & $\begin{array}{c}\text { Temp, } \\
{ }^{\circ} \mathbf{C}\left({ }^{\circ} \mathbf{F}\right)\end{array}$ & $\begin{array}{c}\text { Press, } \\
\mathbf{k P a}(\mathbf{p s i})\end{array}$ & $\begin{array}{c}\text { Temp, } \\
{ }^{\circ} \mathbf{C}\left({ }^{\circ} \mathbf{F}\right)\end{array}$ & $\begin{array}{c}\text { Press, } \\
\mathbf{k P a}(\mathbf{p s i})\end{array}$ & $\begin{array}{c}\text { Temp, } \\
{ }^{\circ} \mathbf{C}\left({ }^{\circ} \mathbf{F}\right)\end{array}$ & $\begin{array}{c}\text { Press, } \\
\mathbf{k P a}(\mathbf{p s i})\end{array}$ & $\begin{array}{c}\text { Temp, } \\
{ }^{\circ} \mathbf{C}\left({ }^{\circ} \mathbf{F}\right)\end{array}$ & $\begin{array}{c}\text { Press, } \\
\mathbf{k P a}(\mathbf{p s i})\end{array}$ & $\begin{array}{c}\text { Temp, } \\
{ }^{\circ} \mathbf{C}\left({ }^{\circ} \mathbf{F}\right)\end{array}$ & $\begin{array}{c}\text { Press, } \\
\mathbf{k P a}(\mathbf{p s i})\end{array}$ \\
\hline 1 & No Heat & $200(29)$ & $100(212)$ & $200(29)$ & $230(445)$ & $690(100)$ & $230(445)$ & $200(29)$ & $280(535)$ & $200(29)$ \\
2 & $185(365)$ & $200(29)$ & $200(392)$ & $200(29)$ & $250(490)$ & $690(100)$ & - & - & $280(535)$ & $340(50)$ \\
3 & $230(445)$ & $460(67)$ & $240(464)$ & $200(29)$ & $280(535)$ & $690(100)$ & $230(445)$ & $480(70)$ & $280(535)$ & $480(70)$ \\
4 & $250(490)$ & $690(100)$ & $275(527)$ & $200(29)$ & $310(590)$ & $690(100)$ & $230(445)$ & $690(100)$ & $280(535)$ & $690(100)$ \\
5 & $280(535)$ & $480(70)$ & & & & & & & \\
6 & $310(590)$ & $690(100)$ & & & & & & & \\
\hline
\end{tabular}

Data were recorded at steady state conditions where variations in pressure and temperature from the desired conditions were kept within $\pm 14 \mathrm{kPa}( \pm 2 \mathrm{psi})$ and $\pm 4^{\circ} \mathrm{C}\left( \pm 7.2^{\circ} \mathrm{F}\right)$, respectively over a 10 -minute period. The reported data represent the averages over the 10-minute period. The SMPS and APS recorded five samples over this period, the $\mathrm{OPC}$ recorded 84, and the CPC recorded 120. In the following figures, the error bars represent one standard deviation of the recorded data over that 10-minute period. For the APS data from Study 1, the standard deviation of the data was not recorded, so in that case the error bars represent an estimated average deviation based on the other data sets. Note that for some of the figures, the random uncertainty was small enough that the error bars are smaller than the figure markers and do not show up on the figure.

\section{Results and Discussion}


Figure 4 shows the size distribution at two different scales for the unheated test case (base study Point 1). This gives a representation of the particulate distribution from the simulator without any elevated temperature and little pressure $(200 \mathrm{kPa})$. For this case, the distribution is predominately sub-micron. This indicates that the combination of the aerosol generator and compressor are producing the desired result: an ultra-fine aerosol. A survey of the measured data from other test cases indicates that the bulk of the distribution always remained in the sub-micron region. In order to properly interpret the data, for an aerosol in this size range, it must be noted that the APS and the OPC, which only can detect particles larger than 0.532 and $0.3 \mu \mathrm{m}$ respectively, only measure the upper tail of the actual distribution, while the SMPS measures essentially the full distribution. Because of this situation, the reported means from the APS and OPC are skewed to the small side of the respective size-measurement range and do not give a true description of the actual distribution's behavior.
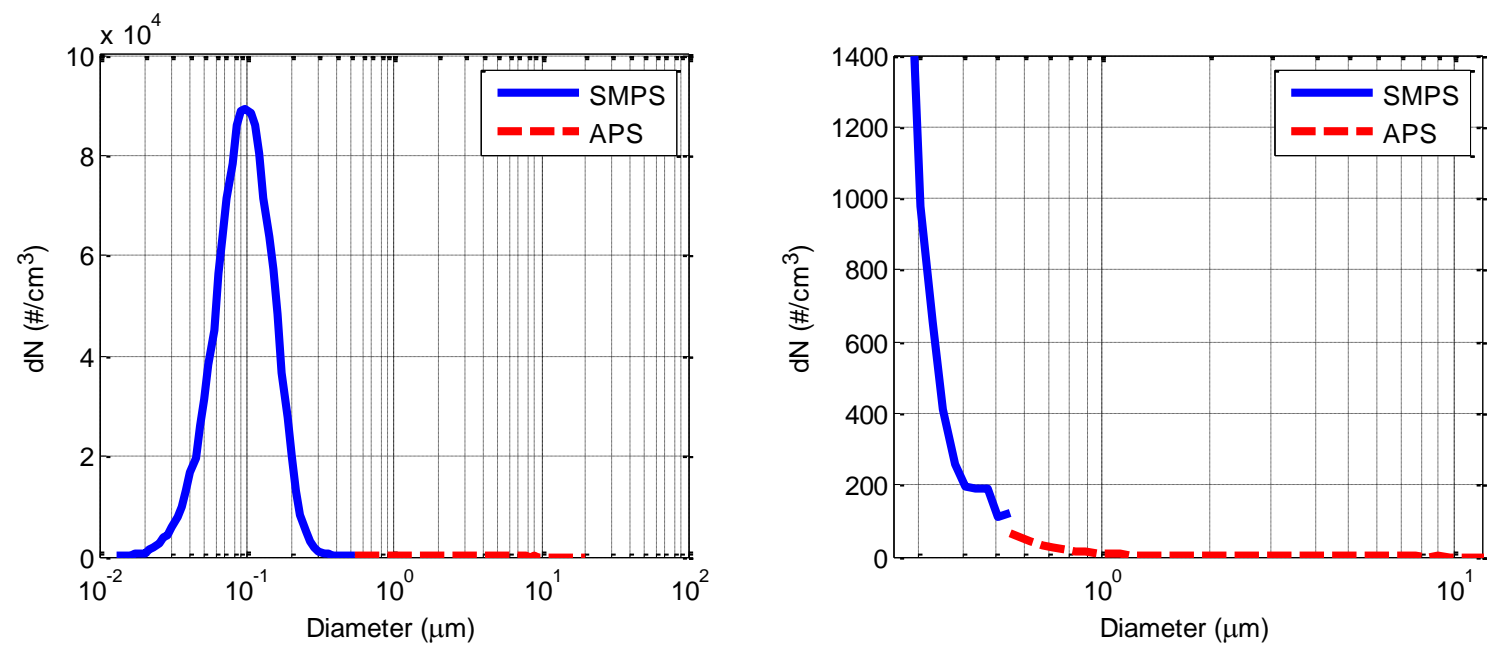

Figure 4. Overlay of SMPS and APS size distributions

Figure 5 presents a plot of the shift of the arithmetic mean of the particle-size distribution versus temperature for the three instruments (the CPC does not bin the size). There is a marked shift in the mean diameter measured by the SMPS between the $185^{\circ} \mathrm{C}\left(365^{\circ} \mathrm{F}\right)$ and $230^{\circ} \mathrm{C}\left(446^{\circ} \mathrm{F}\right)$ points. The mean diameters shown by the APS and OPC also decrease, but only slightly, since the means for their size ranges do not completely describe the actual distribution. Actual shift of the distribution is evident from Table 3; the mean diameter changes from $0.106 \mu \mathrm{m}$ to $0.045 \mu \mathrm{m}$. The lower value at $230^{\circ} \mathrm{C}\left(446^{\circ} \mathrm{F}\right)$ may be an anomaly due to systemic variation but could also be a real phenomenon. Unfortunately, the SMPS was not available to perform multiple independent measurements which would be required to distinguish this. 


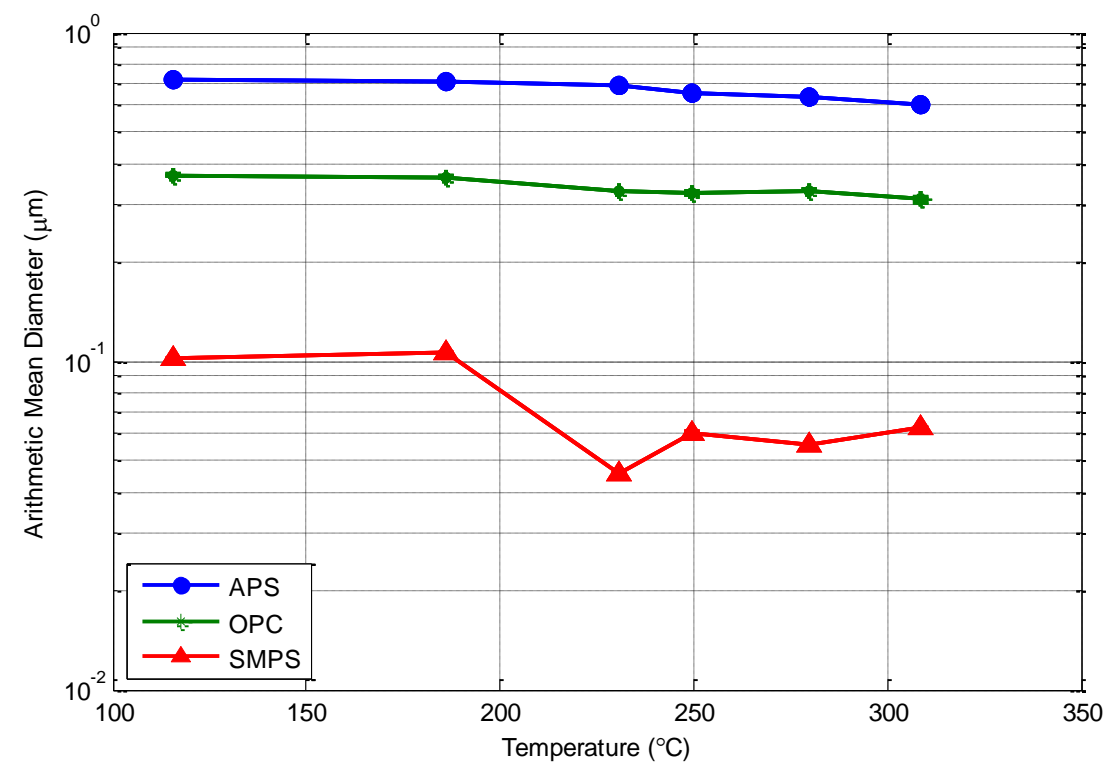

Figure 5. Arithmetic mean particle diameter vs. temperature for the APS, OPC, and SMPS. Error bars show one standard deviation. Some error bars are smaller the symbol.

Table 3. Mean diameters from the base test conditions

\begin{tabular}{ccccccc}
\hline Point & 1 & 2 & 3 & 4 & 5 & 6 \\
\hline Temp, ${ }^{\circ} \mathbf{C}(\mathbf{F})$ & $115.7(240.2)$ & $186.1(366.9)$ & $230.9(447.6)$ & $249.4(480.9)$ & $279.9(535.9)$ & $308.5(587.3)$ \\
Press, kPa (psi) & $198.0(28.7)$ & $202.2(29.3)$ & $464.8(67.4)$ & $710.1(103.0)$ & $479.7(69.6)$ & $699.1(101.4)$ \\
APS, $\boldsymbol{\mu m}$ & 0.718 & 0.707 & 0.687 & 0.651 & 0.641 & 0.606 \\
OPC, $\boldsymbol{\mu m}$ & 0.368 & 0.362 & 0.329 & 0.326 & 0.331 & 0.311 \\
SMPS, $\boldsymbol{\mu m}$ & 0.102 & 0.106 & 0.046 & 0.055 & 0.060 & 0.063 \\
\hline
\end{tabular}

While the SMPS was not available to validate this downward shift through multiple runs, several tests at the same operating conditions were performed with the APS and the OPC. Figure 6 shows the mean size versus temperature for three independent tests with the APS and the OPC. The two additional repetitions have a similar trend to those captured along with the SMPS, indicating that at least for the larger particles, this downward shift is consistent. 


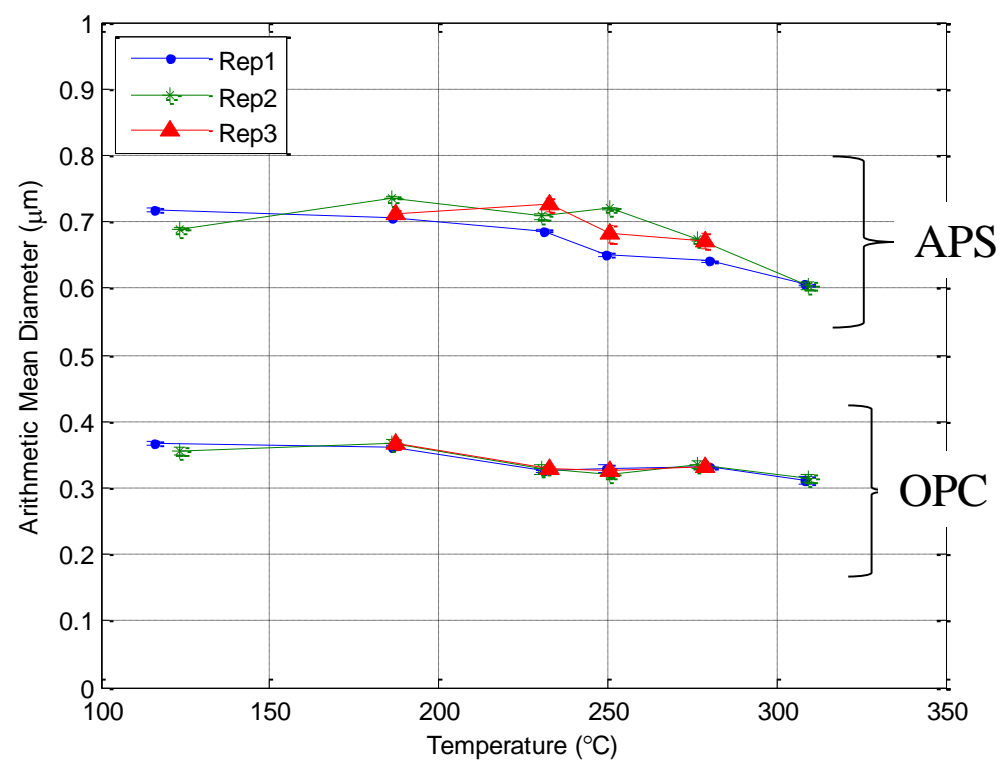

Figure 6. Mean particle diameter from the APS and OPC for three independent repetitions. Error bars show one standard deviation. Some error bars are smaller the symbol.

Table 4 shows the particle concentration from each of the instruments for the base study. The SMPS recorded an order of magnitude increase in particle concentration between $185^{\circ} \mathrm{C}\left(365^{\circ} \mathrm{F}\right)$ and $230^{\circ} \mathrm{C}\left(446^{\circ} \mathrm{F}\right)$. The $\mathrm{CPC}$, which measures a similar size range, shows a comparable trend with two discrepancies: the trend breaks down at the highest temperature, and the absolute value of the concentration is an order of magnitude less than the SMPS. Neglecting these discrepancies (which will be addressed later), the concentration results from these two instruments indicate a substantial increase of fine particles as the temperature is increased. Furthermore, as the data from the SMPS shows even at the highest temperatures and pressures, the ultra-fine particles persist in high concentration.

Table 4. Particle concentration at various temperatures and pressures

\begin{tabular}{|c|c|c|c|c|c|c|}
\hline Point & 1 & 2 & 3 & 4 & 5 & 6 \\
\hline React Temp, ${ }^{\circ} \mathbf{C}\left({ }^{\circ} \mathbf{F}\right)$ & $\begin{array}{c}115.7 \\
(240.2)\end{array}$ & $\begin{array}{c}186.1 \\
(366.9)\end{array}$ & $\begin{array}{c}230.9 \\
(447.6)\end{array}$ & $\begin{array}{r}249.4 \\
(480.9)\end{array}$ & $\begin{array}{c}279.9 \\
(535.9)\end{array}$ & $\begin{array}{c}308.5 \\
(587.3)\end{array}$ \\
\hline React Press, kPa (psi) & $\begin{array}{l}198.0 \\
(28.7)\end{array}$ & $\begin{array}{l}202.2 \\
(29.3)\end{array}$ & $\begin{array}{l}464.8 \\
(67.4)\end{array}$ & $\begin{array}{c}710.1 \\
(103.0)\end{array}$ & $\begin{array}{l}479.7 \\
(69.6)\end{array}$ & $\begin{array}{c}699.1 \\
(101.4)\end{array}$ \\
\hline $\begin{array}{c}\text { APS, } \\
\# / \mathrm{cm}^{3}\left(\# / \mathbf{f t}^{3}\right)\end{array}$ & $\begin{array}{c}789 \\
(2.23 \mathrm{e} 7)\end{array}$ & $\begin{array}{l}1286 \\
(3.64 \mathrm{e} 7)\end{array}$ & $\begin{array}{l}2733 \\
(7.74 \mathrm{e} 7)\end{array}$ & $\begin{array}{l}1465 \\
(4.15 \mathrm{e} 7)\end{array}$ & $\begin{array}{c}97 \\
(2.75 \mathrm{e} 6)\end{array}$ & $\begin{array}{c}14 \\
(3.96 \mathrm{e} 5)\end{array}$ \\
\hline $\begin{array}{c}\text { OPC, } \\
\# / \mathrm{cm}^{3}\left(\# / \mathbf{f t}^{3}\right)\end{array}$ & $\begin{array}{c}534 \\
(1.51 \mathrm{e} 7)\end{array}$ & $\begin{array}{c}927 \\
(2.62 \mathrm{e} 7)\end{array}$ & $\begin{array}{l}2702 \\
(7.65 \mathrm{e} 7)\end{array}$ & $\begin{array}{l}1211 \\
(3.43 \mathrm{e} 7)\end{array}$ & $\begin{array}{c}80 \\
(2.27 \mathrm{e} 6)\end{array}$ & $\begin{array}{c}72 \\
(2.04 \mathrm{e} 6)\end{array}$ \\
\hline $\begin{array}{c}\text { CPC, } \\
\# / \mathbf{c m}^{3}\left(\# / \mathbf{f t}^{3}\right)\end{array}$ & $\begin{array}{l}59,267 \\
(1.68 \mathrm{e} 9)\end{array}$ & $\begin{array}{l}63,908 \\
(1.81 \mathrm{e} 9)\end{array}$ & $\begin{array}{c}114,063 \\
(3.23 \mathrm{e} 9)\end{array}$ & $\begin{array}{c}106,610 \\
(3.02 \mathrm{e} 9)\end{array}$ & $\begin{array}{c}135,270 \\
(3.83 \mathrm{e} 9)\end{array}$ & $\begin{array}{l}62,481 \\
(1.77 \mathrm{e} 9)\end{array}$ \\
\hline $\begin{array}{c}\text { SMPS, } \\
\# / \mathrm{cm}^{3}\left(\# / \mathbf{f t}^{3}\right)\end{array}$ & $\begin{array}{r}1,378,000 \\
(3.90 \mathrm{e} 10)\end{array}$ & $\begin{array}{r}1,658,000 \\
(4.69 \mathrm{e} 10)\end{array}$ & $\begin{array}{r}13,140,000 \\
(3.72 \mathrm{e} 11)\end{array}$ & $\begin{array}{r}16,720,000 \\
(4.73 \mathrm{e} 11)\end{array}$ & $\begin{array}{r}18,160,000 \\
(5.14 \mathrm{e} 11)\end{array}$ & $\begin{array}{r}18,900,000 \\
(5.35 \mathrm{e} 11)\end{array}$ \\
\hline
\end{tabular}


This shift is illustrated well in a comparison between particle-size distributions from the SMPS for the $185^{\circ} \mathrm{C}$ $\left(365^{\circ} \mathrm{F}\right)$ and $230^{\circ} \mathrm{C}\left(446^{\circ} \mathrm{F}\right)$ points, as shown in Figure 7. The particle concentration increases significantly during this temperature change.

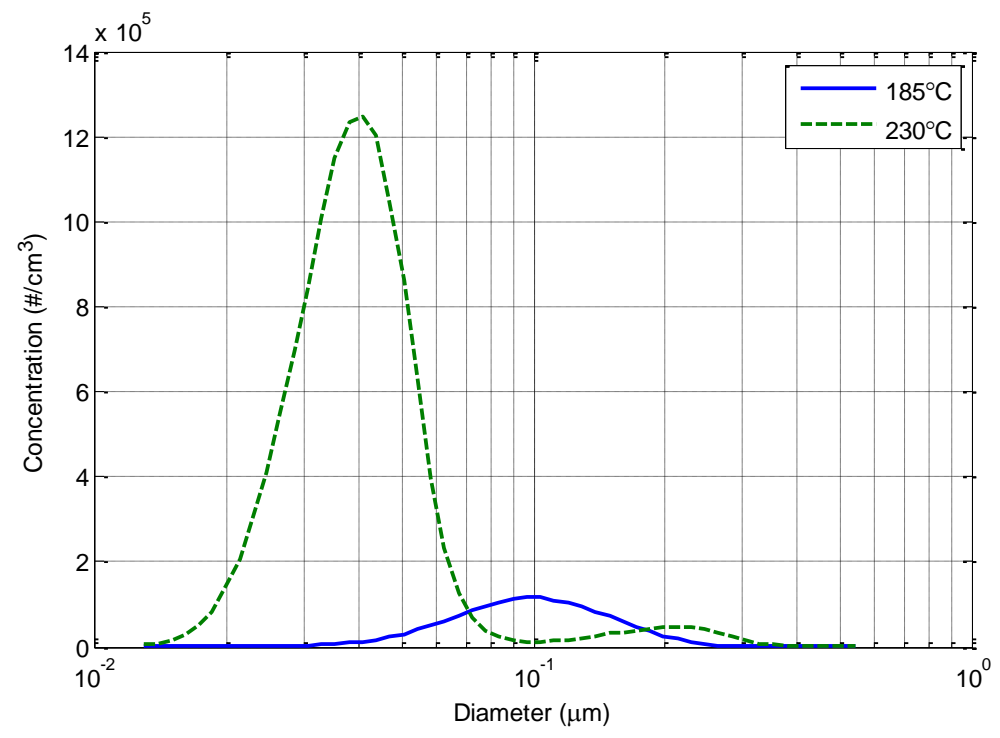

Figure 7. Comparison between the SMPS size distributions at $185^{\circ} \mathrm{C}\left(365^{\circ} \mathrm{F}\right)$ and $230^{\circ} \mathrm{C}\left(446^{\circ} \mathrm{F}\right)$

Studies 1 through 4 give insight into variations of the particle distributions resulting from orderly pressure or temperature changes. Over all of these studies, the maximum arithmetic mean diameter for the APS was $0.853 \mu \mathrm{m}$ and for the OPC was $0.366 \mu \mathrm{m}$. The fact that these values are very close to the bottom measurement range of the instruments (APS minimum $0.532 \mu \mathrm{m}$, OPC minimum $0.3 \mu \mathrm{m}$ ) validates that the bulk of the size distributions for these simulations was sub-micron. Unfortunately, the SMPS was not available to collect data for these studies.

Figure 8 shows the mean size from Studies 1 and 2. Similar to the base study, the studies show a downward shift in the particle-size distribution with increasing temperature. The magnitude of this shift is not very large because the bulk of the size distribution is sub-micron. 


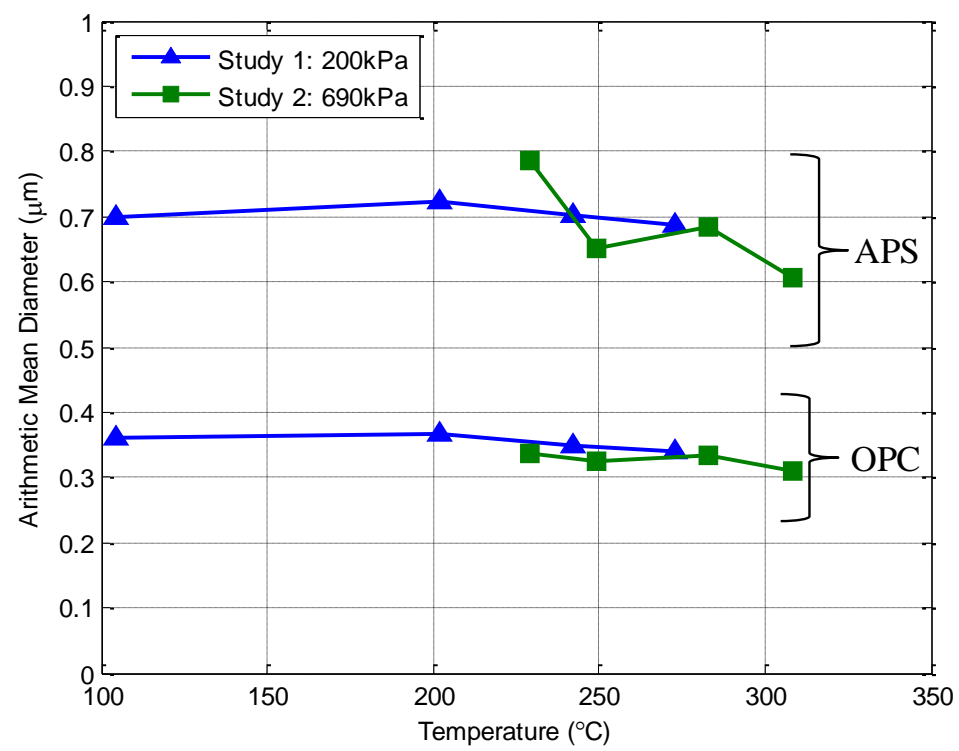

Figure 8. Downward shift in the size distribution with increasing temperature. Error bars show one standard deviation. Some error bars are smaller the symbol.

Figure 9 shows the mean particle diameter from Studies 3 and 4, indicating that there is not a similar trend of decreasing diameter with increasing pressure.

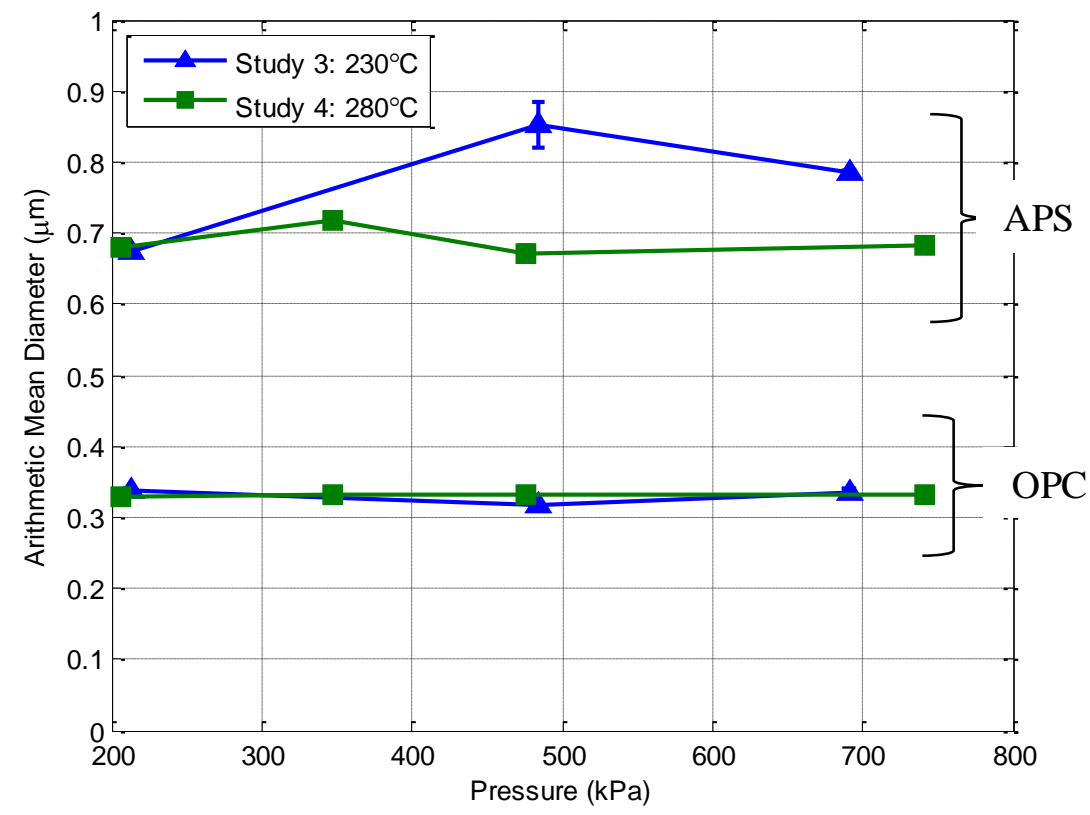

Figure 9. Mean diameter vs. pressure for Studies 3 and 4. Error bars show one standard deviation. Some error bars are smaller the symbol.

Figure 10 shows the particle concentration from the APS for both Studies 1 and 2. The figure shows a significant decrease in the number of particle counts as the temperature increases, which is opposite of the results from the 
SMPS in the base study. This decrease in concentration gives further evidence to a downward shift in the distribution with increased temperature, since the APS and OPC cannot detect the smaller particles. Figure 11 gives the particle concentration of Studies 3 and 4, potentially showing an increase of concentration with increased pressure, although the data are somewhat inconclusive due to the irregular point at $350 \mathrm{kPa}(50 \mathrm{psi})$. Why pressure would have this effect on particle size is not clear.

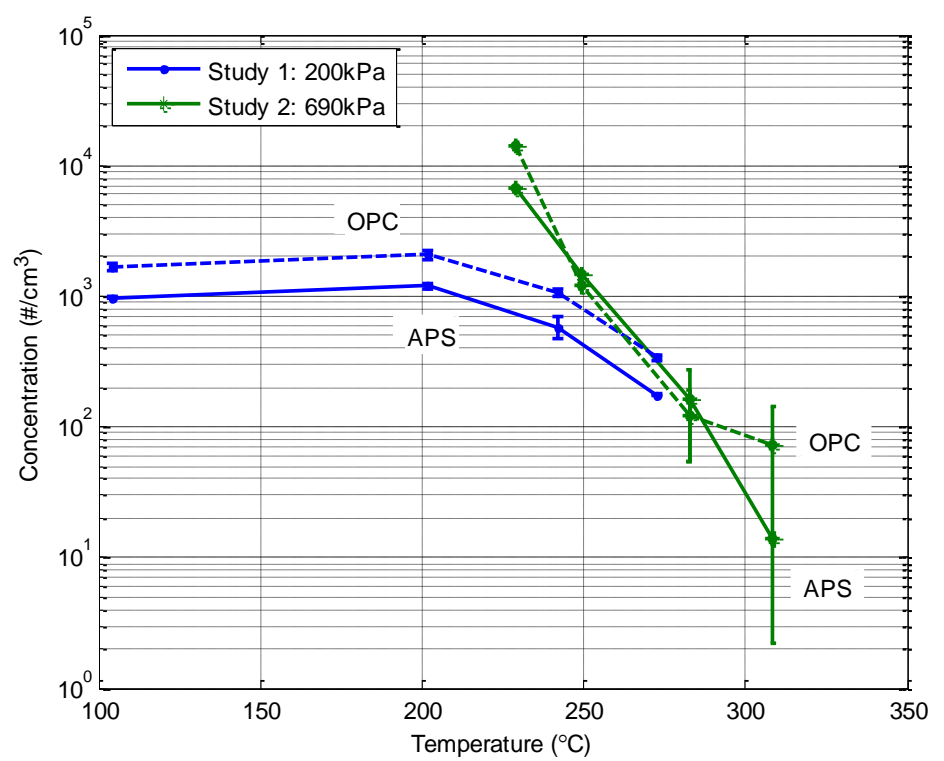

Figure 10. Particle concentration for Studies 1 and 2. Error bars show one standard deviation. Some error bars are smaller the symbol.

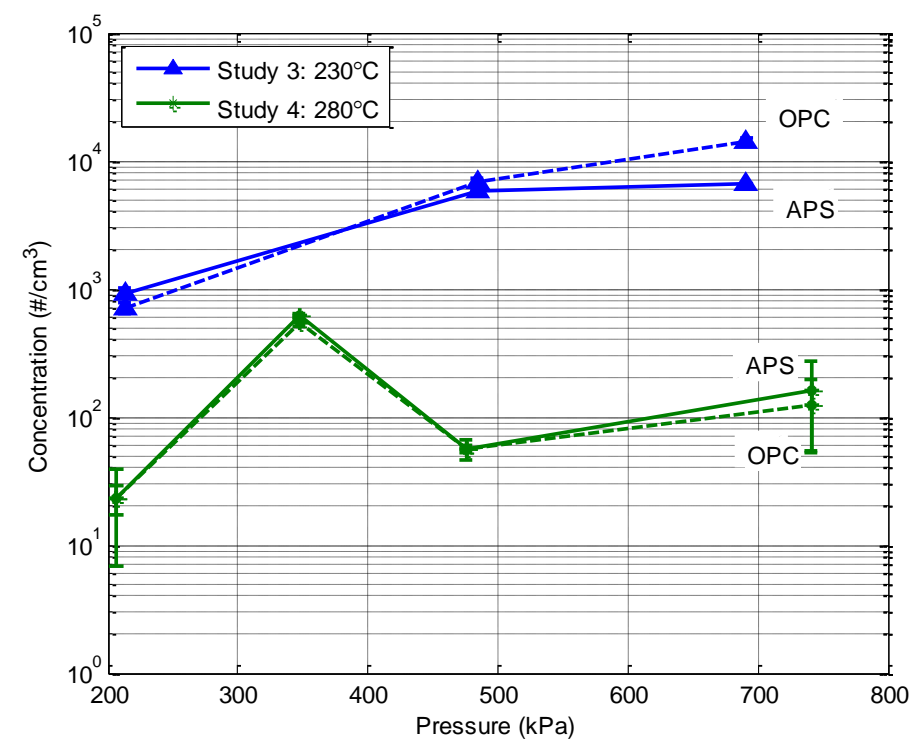

Figure 11. Particle concentration for Studies 3 and 4. Error bars show one standard deviation. Some error bars are smaller the symbol. 
As indicated in Table 4, the CPC does show an increase of concentration with higher temperatures, but the concentration actually drops off at the highest temperature. Not only that, but the CPC registers concentrations much lower (more than an order of magnitude) than the SMPS, even though both instruments measure over the same size range. Since the SMPS and the CPC operate using the same principle (causing a liquid to condense on the small particles until they can be measured), the CPC seems to give erroneous or at least unexpected results. Figure 12 presents the concentration measured by the CPC for all of the data runs verses temperature. The data from Study 1 indicate the same increase of concentration with pressure that the SMPS showed in the base study. However, for the actual base study data, after initially increasing, the concentration again drops off at the highest temperature.

Furthermore, the data from Study 2 indicate that at the higher pressure, the concentration actually decreases with temperature, and while Study 3 shows a repeatable concentration that is not affected by pressure variations at a low temperature, Study 4 shows significant variations in the concentration at a high temperature but different pressures. Repeating the test did not result in a significant change of the CPC concentration trend.

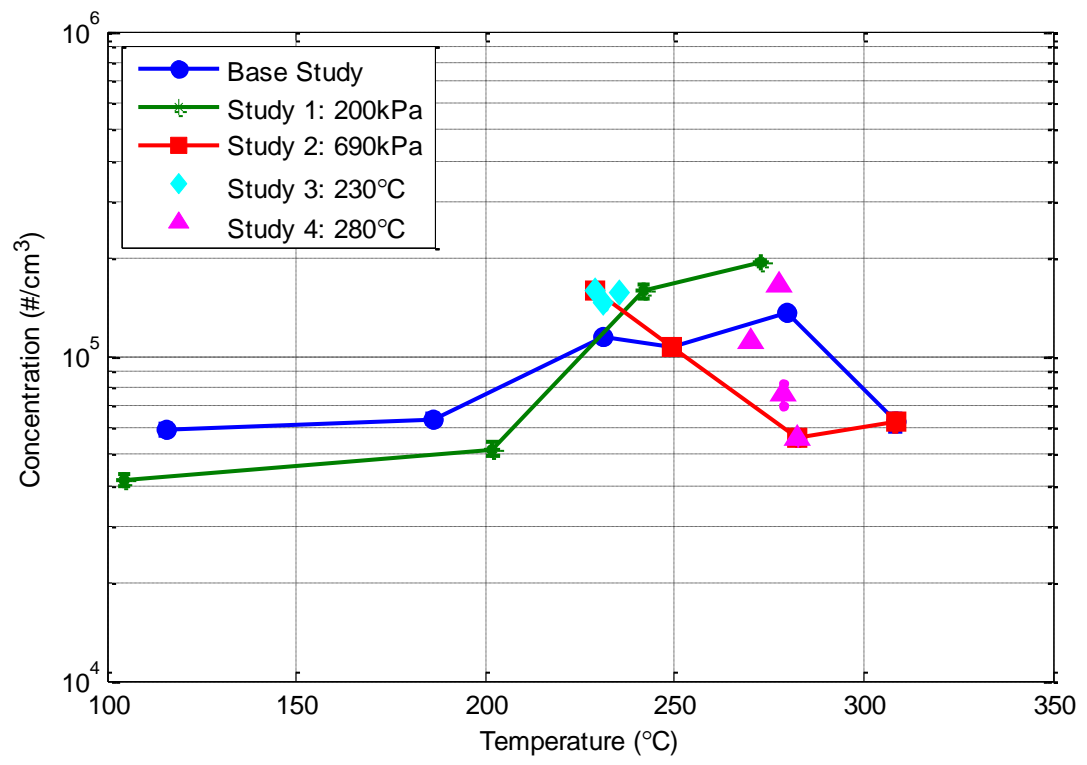

Figure 12. Concentration from the CPC for all of the data runs, showing the inconsistency. Error bars show one standard deviation. Some error bars are smaller the symbol.

The discrepancy in both cases is that the CPC measures fewer particles than the SMPS. Thus, it is very unlikely that the SMPS is the cause of the discrepancy since while it is possible for a particle counter to indicate fewer particles than are actually present, it is not likely that one would measure more. A possible cause for the reduced counting efficiency of the CPC has been identified. The CPC operates using water, while the SMPS operates using butanol. 
The oil in the bleed air is immiscible with the water but is miscible with the butanol. The manufacturer of the CPC indicated that a water-based condensation particle counter could underestimate the concentration of very small particles of pure oil because of this effect (Mann 2012). Keller, Tritscher, and Burtscher also demonstrated a decrease in efficiency when using water-based condensation particle counters with immiscible particles (Keller, Tritscher et al. 2013). This is possibly the reason for the lower counts measured by the CPC. Furthermore, irregularities in the concentration trend with temperature could also be due to the reduced counting efficiency since the signal-to-noise ratio is likely to be much lower at an artificially reduced concentration level.

In summary, significant evidence from these data shows that as the temperature of the oil aerosol increases, a downward shift in the size distribution follows. Additionally, at high temperatures similar to those experienced by the bleed air during normal operation, the oil aerosol showed a substantial increase in ultra-fine, sub-micron particles. The increase in fine particles is likely due to the oil aerosol generating smoke at the high temperatures. These added smoke particles along with the evaporation of semi-volatiles in the oil are likely the cause of the downward shift in particle size. The increase of ultra-fines would likely provide a useful indicator of a bleed air incident. Unfortunately, since the increase in concentration is in the sub-micron region, optical or aerodynamic particles counters do not have the range to accurately detect the phenomena. Additionally, results from the waterbased CPC did not give a consistent measurement of the concentration, possibly because the condensate was not miscible with the oil droplets. Based on these results, water-based particle counters may also be a poor choice as a sensor for detecting a bleed air incident, although further assessment is necessary. This would be a significant result since most organic condensates would pose a safety hazard for use on-board an aircraft. Since the research reported here focused on detailed characterization of the particulates, identifying specific technology that might be used for detection purposes in aircraft applications would serve as an appropriate next-step for the project. The presence of substantial concentrations of ultrafine particles under all conditions does, however, point toward the possible suitability of simple ultrafine detectors, such as used in ionization type smoke detectors, for detection purposes.

\section{Conclusions}

In this paper, size and concentration characteristics of aerosols from a simulated bleed air incident were measured to determine the effect of bleed air temperature and pressure on these aerosols. Size distributions and concentrations were measured with variations in both the temperature and pressure of the bleed air. Results indicate the size range of 
the particulate distribution shifts downward with increasing temperature, and this downward shift is associated with a substantial increase of ultra-fine particles. Pressure had little discernible effect on the aerosol characteristics. This change with temperature is a previously unknown result which will help in future analysis and detection of bleed air incidents and the development of sensors for this purpose. This characteristic phenomena is difficult to detect with an optical or aerodynamic particle counter since the size distribution is predominately sub-micron. Additionally, there was some indication that the ultra-fine particles cannot be accurately measured with a water-based condensation particle counter. Future work regarding development of a sensor to detect ultra-fine particles may need to avoid waterbased condensation particle counting to ensure robust detection.

\section{References}

ASHRAE 2007. ANSI/ASHRAE Standard 161, Air Quality within Commercial Aircraft American Society of Heating Refrigerating and Air-Conditioning Engineers, Atlanta.

Australia. Parliament. Senate. Senate Rural and Regional Affairs and Transport References Committee. October 2000. Air Safety and Cabin Air Quality in the BAe 146 Aircraft. Canberra: Senate Printing Unit

Bartl, P., C. Völkl, and M. Kaiser. 2008. Chemical characterization of polyol ester aviation lubricant residues. Journal of Synthetic Lubrication, 25(1):1-16.

Buck, A., M.I. Roberts, and R. Overfelt, Transient Response Characteristics of Electrochemical Carbon Monoxide Sensors, in 43rd International Conference on Environmental Systems. 2013, American Institute of Aeronautics and Astronautics.

Crane, C., D. Sanders, B. Endecott, and J. Abbott. 1983. Inhalation toxicology: III. Evaluation of thermal degradation products from aircraft and automobile engine oils, aircraft hydraulic fluid, and mineral oil (FAA Publication No. FAA-AM-83-12). Springfield, VA: National Technical Information Service.

Eckels, S. J., B. Jones, G. Mann, K. R. Mohan and C. P. Weisel. 2014. Aircraft Recirculation Filter for Air-Quality and Incident Assessment. Journal of Aircraft 51(1): 320-326.

Hood, E. 2001. Ops cause bad trips? Environmental Health Perspectives, 109(4):A156.

Hunt, E., D. Reid, D. Space, and F. Tilton. 1995. Commercial airliner environmental control system: Engineering aspects of cabin air quality. Aerospace Medical Association Annual Meeting, Anaheim, CA.

Keller, A., T. Tritscher and H. Burtscher. 2013. Performance of water-based CPC 3788 for particles from a propaneflame soot-generator operated with rich fuel/air mixtures. Journal of Aerosol Science 60: 67-72.

Lighty, J. S., J. M. Veranth and A. F. Sarofim (2000). Combustion aerosols: factors governing their size and composition and implications to human health. Journal of the Air \& Waste Management Association 50(9): 1565-1618.

Magoha, P. W. (2012). Incident-response monitoring technologies for aircraft cabin air quality. Ph.D. Dissertation, Kansas State University. 
Mann, G. with TSI Incorporated, Shoreview, MN. E-mail with the author, May 18, 2012.

National Research Council. Committee on Air Quality in Passenger Cabins of Commercial Aircraft, Board on Environmental Studies and Toxicology. 2002. The Airliner Cabin Environment and the Health of Passengers and Crew. Washington, DC: National Academies Press.Overfelt, R., B. Jones, S. Loo, R. Haney, A. Neer, J. Andress, X. Yang, A. Zitova, B. Prorok, J. Fergus, A. Simonian, J. Kiepert, M. Pook, M. Anderson. 2012. Sensors and prognostics to mitigate bleed air contamination events (FAA Publication No. RITE-ACERCoE-2012-TBD). Auburn, AL: National Air Transportation Center of Excellence RITE/ACER. http://acercoe.org/files/bleedairreport.pdf

Pedrosa, V., R. Epur, J. Benton, R. Overfelt, and A. Simonian. 2009. Copper nanoparticles and carbon nanotubesbased electrochemical sensing system for fast identification of tricresyl-phosphate in aqueous samples and air. Sensors and Actuators B: Chemical, 140(1):92-97.

Siegmann, K. and K. Sattler. 1996. Aerosol from hot cooking oil, a possible health hazard. Journal of Aerosol Science 27: S493-S494.

Van Netten, C. 1999. Multi-elemental analysis of jet engine lubricating oils and hydraulic fluids and their implication in aircraft air quality incidents. Science of the Total Environment, 229(1):125-129.

Van Netten, C. 2005. Aircraft air quality incidents, symptoms, exposures and possible solutions. Air Quality in Airplane Cabins and Similar Enclosed Spaces, pages 193-210.

Van Netten, C. and V. Leung. 2000. Comparison of the constituents of two jet engine lubricating oils and their volatile pyrolytic degradation products. Applied Occupational and Environmental Hygiene, 15(3):277-283.

Van Netten, C. and V. Leung. 2001. Hydraulic fluids and jet engine oil: pyrolysis and aircraft air quality. Archives of Environmental Health: An International Journal, 56(2):181-186.

Winder, C. and J. Balouet. 2000. Aerotoxic syndrome: adverse health effects following exposure to jet oil mist during commercial flights. In Proceedings of the International Congress on Occupational Health Conference, 4-6 September, Brisbane, Australia.

Winder, C. and J. Balouet. 2001. Symptoms of irritation and toxicity in aircrew as a result of exposure to airborne chemicals in aircraft. Journal of Occupational Health and Safety-Australia and New Zealand, 17:471-483.

Winder, C. and J. Balouet. 2002. The toxicity of commercial jet oils. Environmental Research, 89(2):146-164. 